\title{
Interactive comment on "The impact of fluctuations and correlations in droplet growth by collision-coalescence revisited. Part II: Observational evidence of gel formation in warm clouds” by Lester Alfonso et al.
}

Anonymous Referee \#2

Received and published: 30 August 2019

The present manuscript is a follow-up article from the authors about cloud droplet collision-coalescence processes, which sought an answer to why the models take a longer time to form precipitation droplets than the observations suggests. Authors describe in their earlier article this is because of a few large droplets getting formed first, which then more efficiently collect smaller droplets in the collision-coalescence process and get bigger faster than others.

Authors perform an ensemble of simulations using the method developed by them and described in their earlier article. Then, they look into the frequency distribution of the 
largest droplet radius across the number of simulations in the ensemble. Authors show that the frequency distribution is a sum of Gumbel and Gaussian distribution, and as the length of simulation time is increased, the weight of Gaussian distribution increases. Authors also show the frequency distribution of the largest droplet in a record of 4 hours of fog data is a sum of Gumbel and Gaussian distribution. The frequency distributions of maximum droplet size, as noticed in simulations and observations are held as evidence of the hypothesis mentioned in the beginning.

My primary contention is that the authors don't show why the said hypothesis (authors call it sol-gel hypothesis) will lead to a particular frequency distribution of the size of the biggest droplets or the shown size distribution is unique to only this hypothesis. Second, the connection between observed frequency distribution in fog data and simulations is tenious. Third, sufficient details are not provided to ascertain whether the frequency distribution as the sum of two distributions with a particular value of weighting factor is better than say if only one of the distribution (that is weighting factor either zero or one) was fitted.

I am unconvinced that the manuscript presents observational evidence of gel formation in warm clouds.

Interactive comment on Atmos. Chem. Phys. Discuss., https://doi.org/10.5194/acp-2018-1210, 2019. 